\title{
Sustaining School Improvement
}

\author{
DAVID F. BOWER
}

Ohio University (USA)

\begin{abstract}
Complexity theory offers new concepts such as self-organization and emergence that may assist schools to find more holistic ways to sustain reform and improvement. The article summarizes a qualitative phenomenological study that examined the experiences of the staff of one middle school in order to better understand the phenomena of self-organization and its role in sustaining school improvement. Self-organization and renewal sustain reform and improvement indirectly and are also related to emergence. Leadership supports and sustains the dynamics of self-organization, renewal, and improvement in individual and collective ways. This study suggests that processes of self-organization can help schools to sustain reform and improvement by internalizing purpose and focus.
\end{abstract}

\section{Introduction}

Demands for better schools have led to a jumble of reform strategies that have been imposed on schools in the form of programs, policies, and laws. Mandates and directions for educational reform often come from outside the educational system, from governors, legislatures, and business leaders (Kelly, 1999) and often include more standardized testing, more accountability, higher standards, and punishments for low-performing schools. Many imposed reform plans actually reinforce the very system that reformers want to change by ignoring the history of public education, the structures 
that support schools, and natural internal dynamics. Without a knowledge base, reform efforts may actually perpetuate the system (Tye, 2000).

Quantum theory and complexity science remind us that our world is unified. Many problems with school reform stem from continuing to use mechanistic views to examine parts of problems rather than the whole and the context. The concept of self-organization gives us a new perspective. Self-organization refers to how an organization looks within itself to find self-supporting dynamics.

Complex systems are distinguished by a capacity for self-organization, that is, the ability to rearrange and reform their patterns of operation in mutual adaptation to changing needs and capacities of their components as well as changing demands and opportunities from the environment. The distinguishing characteristic of this process is that it occurs as a result of communication, selection, and adaptation processes within the system itself and between the evolving system and its environment. It is not imposed externally. The result is a new and more constructive order in dynamic response to a changing environment. (Comfort, 1994, p. 4)

Pascale, Milleman, and Gioja (2000) say that properties of self-organization "enable a system or organization to tap its own latent potential to defend, innovate, and transform itself" (p. 117).

\section{School History}

In some ways, our large urban schools are collections of one-room schools, now called classrooms, that are characterized by autonomy, isolation, and routine. Schools are rooted in mechanistic and behaviorist practices that developed during the days of one-room schools (Tye, 2000, p. 32). Tye (p. 3) refers to this phenomenon as the "deep structure" of schooling. It is not difficult to find agreement with the suggestion that schools should look and function much as they have for the last several decades. Tye concludes, "... [r]eforms of any kind won't 'stick' unless they are compatible with the existing deep structure of the society or with the direction in which the deep structure may be shifting" (p. 4).

Our system of education is based on a machine model from the early 1900's. Frederick Winslow Taylor, in his 1911 The Principles of Scientific Management, imposed the Newtonian machine model on organizations. He focused his efforts on identifying parts of a system so that individual parts could be studied and improved. Taylorism helped to shape the modern Industrial Age, including command and control styles of leadership and management (Lewin, 1999).

Usdan and Cuban (2002) note the challenge of sustaining reform work within this context. "One of the sources of greatest frustration to advocates 
of education improvement has been the difficulty of sustaining reform initiatives. Our title [Powerful reform with shallow roots] acknowledges this reality and the difficulty of 'scaling up'" (p. 40). Wheatley (2001b) sees a similar problem in organizations, commenting that "the clash with old beliefs and images occurs as soon as we embark on the task of creating an organization. We move back to the machine ideas about structures, roles, designs, and leaders. We create organizations from the outside ..." (p. 10).

Research and literature on educational reform is abundant. Much of the reform literature tells stories of reform initiatives, projects, and programs by documenting successful implementation. Few stories reveal how long these reform initiatives last. Not long, says Barbara Tye (2000):

If they did, we would already know much more than we do about the dynamics of the deep structure: those forces that come into play during the third, fourth, fifth, sixth year and beyond, and that alter the innovations so much that in most cases, 10 years after a school (any school you care to name) adopts a change-whether of structure, pedagogy, or curriculumyou can walk into the school and find not a trace of that innovation remaining-except in the memories of the old-timers on the faculty. (p. 5)

This quote by Tye was the starting point for a study of the school where I served as principal (Bower, 2003). Many school reform initiatives were not only sustained but were moving into a second decade of continued refinement and development. Clearly something was sustaining this work. By examining this phenomenon through the lens of complexity theory I was able to learn more about self-organization, ownership, and emergence.

Data for this study was collected from individual interviews, focus groups, document review, and journal notes. Document review established some school history and the status of improvement efforts. Interview questions explored three research questions and yielded transcriptions that were analyzed. Categories that emerged from the analysis were used to group the transcribed notes. Focus groups confirmed the findings from the individual interviews. The resulting analysis of the data offers an understanding of some of the dynamics of self-organization.

\section{Complexity}

Marion (1999) provides a useful definition to begin an exploration of chaos and complexity:

A complex system is one whose component parts interact with sufficient intricacy that they cannot be predicted by standard linear equations; so many variables are at work in the system that its overall behavior can only be understood as an emergent consequence of the holistic sum of all the myriad behaviors embedded within. (pp. 27-28) 
One way to understand complexity is to view the relationship between complicated and complex systems (Davis et al., 2000, p. 54). Complicated systems may be understood by examining their parts. They are "predictable sums" of those parts (p. 55). Complex systems, however, may not be understood by examining parts; they exceed their parts and may only be understood in relation to the parts. Complex systems are "self-organizing, self-maintaining, dynamic, and adaptive" (p. 55).

\section{Self-Organization and Emergence}

Sustained school improvement is emergent. The following figure shows elements of this process.

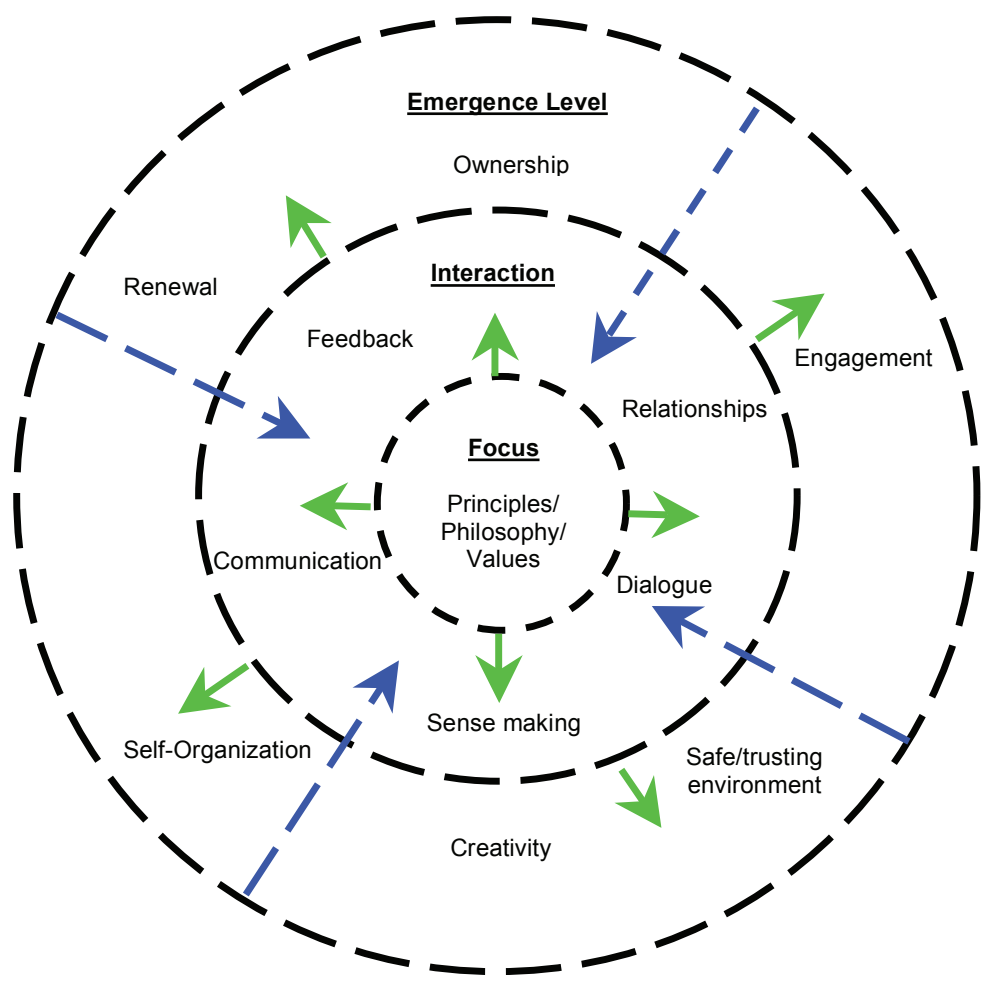

In this study I define reform as sustained improvement over time that emerges from within a school and is based upon the needs that the school has identified from internal and external feedback. Self-organization and emergence are not characterized by what is imposed from without. The core of the organization, characterized by principles, philosophy, and values, influences processes like feedback, communication, dialogue, sense making, and relationships. These processes in turn support what emerges from the 
organization-ownership, renewal, creativity, a safe and trusting environment, engagement, and self-organization.

Self-organizing around a clear philosophy or principles provides a way to give focus without limits. McMaster notes that “... a relatively small set of principles, or attractors, will be sufficient to create the elements by which a system self-organizes" (1996, p. 48). He also says that "... a rich variety of expressions is possible from a simple set of rules or 'attractors' when energy is directed or expressed through them. In the case of corporations, the 'attractors' can be thought of as values, or operating principles" (p. 63).

Interactive processes like conversation and dialogue support the work of internalizing the focus and principles that a school has adopted. These processes provideanimportantlinkbetween theindividualand the collective. Instead of creating a structure that is imposed upon people, behavior is affected because of internal process. By "processes" I am not referring to a mechanistic input/output concept. Rather, the processes described in this study refer to engagement, relationships, and interaction. Redesigning structures does not change people's behaviors, and superficial work does not lead to effective change. "The process of instilling organizational values requires an interactive dialogue" (Maccoby, 1998, p. 55). Ellinor and Gerard (1998) say that information is power. "In a collaborative model, only those who have access to information can contribute effectively" (p. 192). When information is freely provided and structures support conversation and dialogue to use the information, people can engage more productively in their work.

Self-organization and renewal sustain reform and improvement through sense-making, freedom, a safe and supportive environment, and ownership. Ownership seems to depend upon many other factors including principles, freedom, creativity, support, and leadership. Sustained reform and improvement "emerge" from these factors.

Individual and collective sense-making help people to know their place and purpose, or how they fit, within an organization through the related processes of communication and feedback (Weick, 1995). Working in isolation makes it difficult to know how you are doing and how your work fits within the larger parts of a school like a grade level. Interactive processes support sense-making.

Freedom is an important quality that sets a tone in the school and supports conditions that lead to making a difference, engagement, and risk taking. Freedom also allows teachers to create their own work, thus supporting ownership. Ownership may be as specific as a creative teaching unit or as broad as a shared sense of leadership. McMaster (1996) says that "(f)reedom designed with an understanding of complex intelligent systems and their self-organizing nature will lead to positive results beyond our imagining" 
(p. 105). Freedom is part of the sustaining conditions that support emergence and self-organization.

Wheatley (1992) explains that freedom and order, while seeming to be a paradox, actually are partners. Allowing autonomy at the local level creates freedom that finds a natural order through self-organization. The result is more coherence and continuity.

A sense of ownership is an important element in sustaining change and transformation. Wheatley (2001a) says that people who are engaged in the change process can see what is possible; they become advocates for the changes.

Ownership emerges from a number of factors including communication, feedback, shared leadership, and an internalized focus on principles. Wheatley notes that "[a]n organizational community that is clear about its intent knows what it wants to accomplish and knows what its purpose is" (2001a, p. 3). To arrive at this point, an organizational community must find ways to inform itself.

\section{Leadership in a Self-Organized School}

A key question in this study was, "How does leadership support and sustain the dynamics of self-organization, renewal, and improvement?" Leadership supports and sustains the dynamics of self-organization, renewal, and improvement in individual and collective ways. Individual efforts, as described in the data, were mostly those of the principal. Collective leadership allows teachers to see themselves as leaders and to see their collective power to shape the school through various leadership positions.

\section{Individual Leadership}

Individual leadership in a school centers on the role of the principal. When teachers were asked about leadership, their initial responses concerned individual principals and their style, efforts, communication, and effect upon the school. The principal was usually seen as a change agent with change or reform efforts beginning with leadership actions.

One leadership skill that is valued, according to the data in this study, is listening. Several teachers who were interviewed cited the importance of being heard or of being listened to by the principal. Listening may be a simple way to support emergence-to simply listen and allow what is inside to be heard and to take shape through words.

Several teachers noted the buffering effect of principal leadership. Intrusive demands from schooldistricts or stateleveldepartments frequently 
hamper the work of teachers. When a principal can buffer these demands and give teachers the time and space to teach, the teachers felt they could be more effective. The dynamics of self-organization suggest a need for a principal to focus on processes that will in turn support a collective focus on content. This can enable a school to move from individual to collective leadership.

\section{Collective Leadership: Principal and Teachers}

The role of the individual leader must be redefined if leadership is to move from individual to collective. The principal as individual leader will exist in schools that seek to develop self-organizing qualities, but leadership must be distributed throughout the school. The first shift is from individual to collective. Sergiovanni (1992) describes this shift with leader/follower terms. "If self-management is our goal, then leadership will have to be reinvented in a fashion that places 'followership' first" (p. 68).

Collective leadership seems to be based upon sound relationships. One example of collective leadership is a shift from rigid to more fluid roles. For several years at Roosevelt, individuals were almost sentenced to take on leadership roles with various groups and committees. People gave in and accepted the roles to allow meetings to move on. In the last few years, people have moved in and out of leadership roles with relative ease. A term of office lasts a year or so, and there is little difficulty in finding someone new to take on the role. A sense of support and the feeling that "I can do this" seem to characterize this new culture.

Part of this shift may stem from the realization that leaders do not have to "save the day" or become the heroes who will solve all problems. There seems to be a growing sense that leadership is about working with others to solve problems. There is also a sense of safety to take the risk to be a leader.

A shift to collective leadership is also a shift to looking within for answers. While it is the principal who often brings information to a meeting, it is the shared interaction of those at the meeting that produces results. People can work from a core of principles and values to bring a coherent response to emerging needs.

Relationships are the basis of shared leadership and ownership. An essential job for principals is to establish a trusting culture with sound relationships. Santosus (1998) says that a caring culture emerges when organizations focus on maintaining sound relationships. Change becomes easier because people know that they are not alone and that together they can manage the change process.

Collective leadership taps into the power of self-organization and the distributed intelligence that can emerge. Lewin (1999) says that self- 
organized order flows from within and does not depend on imposition from above. Collective leadership also draws on the creativity that exists within organizations (Capra, n.d.).

Leadership is related to the phenomenon of emergence. Leaders are not born or made, but they emerge at the juxtaposition of personal and situational events.

\section{Implications for Leaders}

Ownership suggests a shift in the role of leadership. In a complex, adaptive organization it is less the leader's job to design the organization than to involve others in co-design. Pinchot and Pinchot (1996) note that "[w]orkers will be far more efficient if they have a hand in designing their own work than if work design is employed by management and handed down for compliance. This fact flies in the face of bureaucracy's most basic tenet, that it is the job of management to design and coordinate workers' jobs"' (pp. 6-7).

School leaders are trapped in a world of contradictions. Simultaneously they are to be transformational leaders who are proactive and creative while dealing with demands and mandates that increase dependency (Garmston \& Wellman, 1999). Fullan (1998) says dependency is created by an overload of conflicting and disjointed directives and an over-reliance on pre-packaged solutions. Top-down reengineering fails because it forces people to change what they do without having input or ownership into the change process (Pascale et al., 2000, p. 153). Capra (n.d.) describes how top-down design denies the creative processes that are available when people who will implement the design are left out of the process. People will find their own sense of ownership by circumventing the direction or modifying the design. People support what they create; this creative process is what sustains reform.

Leadership is often described with lists of attributes. Barth (1990) resists these lists, saying that "[a] community of learners seems to work from assumptions fundamentally different from those of the list makers" (p. 45). Barth's description of qualities of leaders includes the capacity to improve themselves: to learn and to contribute to the learning of others; to improve the culture and quality of relationships; and to determine how to sustain learning. The principal doesn't need to be headmaster or instructional leader. He or she must be the head learner who models learning to all. The role as learner allows for new leadership potential to emerge.

Leadership supports and sustains the dynamics of self-organization, renewal, and improvement in individual and collective ways. Listening may be a simple way to support emergence-to simply listen and allow what is inside to be heard and to take shape Intrusive demands from school districts or state level departments frequently hamper the work of teachers. 
When a principal can buffer these demands and give teachers the time and space to teach, the teachers felt they could be more effective.

From a practical perspective, providing resources including time to work with others as well as supplies made the work of teachers easier to handle. Support for risk taking and creative teaching was also important. Valuing and validating creative classroom projects helped to encourage teachers to experiment creatively. Validation could be as simple as visiting classrooms and encouraging teachers to talk about their work at team or faculty meetings.

MacIntosh and MacLean (1999) cite content and process as two divisions of leadership strategy. Principals often focus on content. Content includes a focus on reconfiguration of resources and competencies with an emphasis on equilibrium and control. Process is concerned more with strategic change and innovation. Process emphasizes dynamism and emergence, especially in ways that decisions are made and through the management of strategic change. The focus here is on implementation that allows for emergence. The authors describe this as a focus on "strategic behavior as a phenomenon which emerges in an unpredictable way from the networks of influence and interaction in the organization" (p. 299).

The role of the individual leader must be redefined if leadership is to move from individual to collective. The principal as individual leader will exist in schools that seek to develop self-organizing and sustaining qualities, but leadership must be distributed throughout the school. The first shift is from individual to collective. Sergiovanni (1992) describes this shift with leader/follower terms. "If self-management is our goal, then leadership will have to be reinvented in a fashion that places 'followership' first" (p. 68).

Anderson and Anderson (2001, p. 151) describe three types of leadership styles: controlling, facilitating, and self-organizing. The controlling style results in mandates to "follow the plan." The facilitating style is more responsive to needs to "guide and be influenced." The self-organizing style is the most allowing; "trust the process" is the main descriptor for this style.

In many traditional schools, leadership processes are directed primarily on actions. The process may look like this:

$\begin{array}{cccccc}\text { Leader } & \rightarrow \text { Actions } \\ \text { (Principal) } & \begin{array}{c}\text { (Strategies, } \\ \text { processes, } \\ \text { structures) }\end{array} & & \text { Staff } \rightarrow \begin{array}{c}\text { Results } \\ \text { (Learning, } \\ \text { student } \\ \text { achievement) }\end{array}\end{array}$

In self-organizing schools, leadership processes are directed both towards staff to create shared leadership and towards actions that support 
that leadership. Feedback continually helps the school to self-adjust and respond to changing conditions and needs. The leadership process may look like this:

\begin{tabular}{|c|c|c|c|c|c|c|c|c|}
\hline Leader & $\rightarrow$ & $\begin{array}{c}\text { Actions } \\
\text { with staff }\end{array}$ & $\rightarrow$ & $\begin{array}{c}\text { Shared } \\
\text { leadership }\end{array}$ & $\rightarrow$ & $\begin{array}{l}\text { Collective } \\
\text { actions }\end{array}$ & $\rightarrow$ & $\begin{array}{l}\text { Sustained } \\
\text { results }\end{array}$ \\
\hline & & & & & & & & \\
\hline
\end{tabular}

The role of leadership cannot be just to maintain order. Order based upon rules someone else has created does not allow us to respond to increased demands and complexity of local work. School systems are characterized by the paradox that those leaders who are farthest away from students, such as superintendents, have the most official authority and power. While teachers may not set a direction for an entire school district, they do have personal power. Teachers often exercise their personal power behind the closed doors of classrooms. When teachers are involved collectively in the creation of rules and order, they can collectively assert their power.

\section{Conclusion}

No one can predict how to make an innovative organization work. "All managers can do is to establish the conditions that enable groups of people to learn in each new situation what approaches are effective in handling it" (Stacey, 1992, p. 15). The dynamics of self-organization suggest a need for collective leadership to focus on processes that will in turn support ownership and sustained school improvement. In an era of high-stakes accountability we need fewer models of innovation and improvement and more knowledge about how to sustain the work.

\section{References}

Anderson, D. \& Anderson, L.A. 2001. Beyond change management: Advanced strategies for today's transformational leaders. San Francisco: Jossey-Bass / Pfeiffer.

Barth, R.S. 1990. Improving schools from within: Teachers, parents, and principals can make the difference. San Francisco: Jossey-Bass.

Bower, D.F. 2003. Leadership and the self-organizing school. Albuquerque, NM: University of New Mexico.

Capra, F. N.D. Ecoliteracy: A path with heart. Available: http:/ / www.haven.net/patterns / capra.html

Comfort, L.K. 1994. Self-organization in complex systems. Journal of Public Administration Research and Theory, 4(3): 393-411.

Costa, A.L. \& Garmston, R.J. 1994. Cognitive coaching: A foundation for renaissance schools. Norwood, MA: Chistopher-Gordon Publishers. 
Davis, B., Sumara, D., \& Luce-Kapler, R. 2000. Engaging minds: Learning and teaching in a complex world. Mahwah, NJ: Lawrence Erlbaum Associates.

Ellinor, L., \& Gerard, G. 1998. Dialogue: Rediscover the transforming power of conversation. New York: John Wiley \& Sons.

Fullan, M. 1998. Breaking the bonds of dependency. Educational Leadership, 55(7): 6-10.

Garmston, R., \& Wellman, B. 1999. The adaptive school: A sourcebook for developing collaborative groups. Norwood, MA: Christopher-Gordon Publishers.

Kelly, T. F. 1999. Why state mandates don't work. Phi Delta Kappan, 80(7): 543-546.

Lewin, R. 1999. Complexity: Life at the edge of chaos. Chicago: University of Chicago Press.

Maccoby, M. 1998. Making values work. Research Technology Management, 41(5): 55-58.

MacIntosh, R., \& MacLean, D. 1999. Conditioned emergence: A dissipative structures approach to transformation. Strategic Management Journal 20: 297-316.

Marion, R. 1999. The edge of organization. Thousand Oaks, CA: Sage.

McMaster, M.D. 1996. The intelligence advantage: Organizing for complexity. Boston: Butterworth-Heinemann.

Pascale, R.T., Milleman, M., \& Gioja, L. 2000. Surfing the edge of chaos: The laws of nature and the new laws of business. New York: Crown Business.

Pinchot, G., \& Pinchot, E. 1996. The intelligent organization: Engaging the talent and initiative of everyone in the workplace. San Francisco, CA: Berret-Koehler.

Santosus, M. 1998, April 15. Simple, yet complex. CIO Enterprise Magazine.Available: http://www.cio.archive/enterprise/041598_qanda_content.html

Sergiovanni, T.J. 1992. Moral leadership: Getting to the heart of school improvement._San Francisco: Jossey-Bass.

Stacey, R. 1992. Managing the unknowable: Strategic boundaries between order and chaos in organizations. San Francisco: Jossey-Bass Publishers.

Tye, B. 2000. Hard truths: Uncovering the deep structure of schooling. New York: Teachers College Press.

Usdan, M.D., \& Cuban, L. 2002. Powerful reforms with shallow roots. Education Week 24(4): 37-40.

Weick, K.E. 1995. Sensemaking in organizations. Thousand Oaks, CA: Sage.

Wheatley, M.J. 1992. Leadership and the new science. San Francisco: Berrett-Koehler.

Wheatley, M.J. 2001a. Innovation means relying on everyone's creativity. The Berkana Institute. Available: http: / / www.fromthefourdirections.org/articles/

Wheatley, M.J. 2001b. Reclaiming Gaia, reclaiming life. The Berkana Institute. Available: http:/ / www.fromthefourdirections.org/articles/

\section{About the Author}

David F. Bower, Ed.D., is an assistant professor of teacher education at Ohio University and is coordinator of the Middle Childhood program. He received his bachelor's degree from Grove City College. He earned a Masters degree in Educational Administration and a Doctor of Education degree from the University of New Mexico. Dr. Bower is the former principal of Roosevelt Middle School in Albuquerque, NM. His primary research interests are teacher education and preparation, complexity theory, and organizational dynamics. He may be reached at bowerd@ohio.edu. 
Sustaining School Improvement

(C) Copyright 2006. The author, DAVID F. BOWER, assigns to the University of Alberta and other educational and non-profit institutions a non-exclusive license to use this document for personal use and in courses of instruction provided that the article is used in full and this copyright statement is reproduced. The authors also grant a non-exclusive license to the University of Alberta to publish this document in full on the World Wide Web, and for the document to be published on mirrors on the World Wide Web. Any other usage is prohibited without the express permission of the authors. 